\title{
ARTICULACIÓN DE LOS SISTEMAS DE CALIDAD, CONSEJO NACIONAL DE ACREDITACIÓN (CNA) Y NORMAS NTC - ISO 9001 PARA PROGRAMAS ACADÉMICOS DE EDUCACIÓN SUPERIOR EN INSTITUCIONES PÚBLICAS
}

\section{ARTICULATION OF THE SYSTEMS OF QUALITY, NATIONAL COUNCIL OF ACCREDITATION (CNA) AND STANDARDS NTC - ISO 9001 FOR ACADEMIC PROGRAMS OF HIGHER EDUCATION IN PUBLIC INSTITUTIONS}

ARTICULAÇÃO DOS SISTEMAS DE QUALIDADE, CONSELHO NACIONAL DE ACREDITAÇÃO (CNA) E NORMAS NTC - ISO 9001 PARA PROGRAMAS ACADÊMICOS DE ENSINO SUPERIOR EM INSTITUIÇÕES PÚBLICAS

GONZÁLEZ MUÑOZ_Ingrid Brigitt, RAMÍREZ GÓMEZ _ Carlos Arturo

Estudiante Décimo Semestre Administración de Empresas, Universidad De Nariño. Monitora Aseguramiento de la Calidad, Administración de Empresas, Universidad De Nariño. Email: ibrgittgonzalez@gmail.com, Colombia.

Especialista en Mercadeo, Universidad de Bogotá Jorge Tadeo Lozano.

Docente investigador, Administración de Empresas, Universidad De Nariño. Email: villadiegocarlos@gmail.com, Colombia.

Recibido: 16 de mayo de 2017 Aprobación definitiva: 15 de junio de 2018

DOI: http://dx.doi.org/10.22267/rtend.181901.93

\section{RESUMEN}

Los programas de pregrado de educación superior pública colombiana se enfrentan a dos sistemas de gestión de calidad para aproximarse a un juicio de valor sobre la excelencia de la formación académica impartida y del impacto en la sociedad: de un lado están los lineamientos de acreditación para programas de pregrado y de otro, las normas técnicas de calidad ISO 9001:2015 y NTC GP 1000:2009. 
Asimismo, se debe rendir examen ante instituciones disímiles como el Ministerio de Educación Nacional y el Instituto Colombiano de Normas Técnicas ICONTEC. Esta situación provoca hasta cierto punto visiones fragmentadas sobre el nivel de calidad de los programas de pregrado de educación superior, lo que conlleva a darle más importancia a un sistema que a otro.

Este artículo apunta a unificar los dos sistemas de calidad, en una matriz de congruencia, de tal manera que se incluyan requerimientos de las normas ISO y NTC en factores CNA.

Este artículo es producto de una investigación y recoge los primeros resultados de la misma, en la cual se realizó una revisión sistémica de normas de calidad en educación, se participó activamente en procesos de autoevaluación y acreditación y se consultó a expertos en ambos sistemas de calidad.

Palabras clave: Calidad; Programas Pregrado Educación Superior; Acreditación; Articulación; NTC GP 1000:2009; ISO 9001:2015.

JEL: M15, M11, O32

\section{ABSTRACT}

Undergraduate programmes of public higher education, the colombian will face two quality management systems to approximate a value judgment about the excellence of the education provided and the impact on society: on the one hand are the guidelines for accreditation of undergraduate programs and the standards of quality ISO 9001:2015 and NTC GP 1000:2009.

Also, you must take the exam before institutions as disparate as the Ministry of National Education and the Colombian Institute of Technical Standards ICONTEC. This situation leads to a certain extent fragmented perspectives on the level of quality of the undergraduate programs of higher education, which leads to give more importance to one system to another. 
This article aims to unify the two systems of quality, in a matrix of congruence, in such a way to include requirements of ISO standards and NTC on factors CNA.

This article is the product of a research and collect the first results of the same, in which a review was conducted of systemic standards of quality in education, actively participated in processes of self-evaluation and accreditation, and has consulted experts in both quality systems.

Keywords: Quality; Programs Undergraduate Higher Education; Accreditation; Articulation; NTC GP 1000:2009; ISO 9001:2015. JEL: M15, M11, O32

\section{RESUMO}

Os programas de graduação da educação superior pública colombiana enfrentam dois sistemas de gestão de qualidade, para chegar a um juízo de valor sobre a excelência da formação ministrada e do seu impacto na sociedade: de um lado estão as diretrizes de credenciamento para programas de graduação e de outro, as normas técnicas de qualidade ISO 9001:2015 e NTC GP 1000:2009.

Além disso, devem prestar exame perante instituições diferentes, como o Ministério de Educação Nacional e o Instituto Colombiano de Normas Técnicas ICONTEC. Esta situação provoca, até certo ponto, visões fragmentadas sobre o nível de qualidade dos programas de graduação da educação superior, o que implica a dar mais importância a um sistema para outro.

Este artigo visa a unificar os dois sistemas de qualidade, em uma matriz de convergência, de tal forma que se incluam requisitos das normas ISO e NTC em fatores CNA.

Este artigo é produto de uma pesquisa e recolha os primeiros resultados da mesma, na qual se realizou uma revisão sistemática de normas de qualidade em educação, participou ativamente em processos de autoavaliação e de acreditação e se consultou especialistas em ambos os sistemas de qualidade. 
Palavras-chave: Qualidade; Programas de Graduação da Educação Superior; Acreditação; Articulação; NTC GP 1000:2009, ISO 9001:2015. JEL: M15, M11, O32

\section{INTRODUCCIÓN}

Una de las palancas para el crecimiento y desarrollo de la educación superior, es su calidad como fuente de competitividad que permite enfrentar las exigencias del mundo moderno; en las últimas décadas la educación superior de la mayoría de los países se ha caracterizado por el crecimiento y por ofrecer una amplia variedad de programas de formación y surge la necesidad de enfocarse en políticas basadas en la calidad de los resultados del aprendizaje.

Colombia no es una excepción a esta tendencia, actualmente la Universidad Pública Colombiana va en dirección a la competitividad académica, en función del mejoramiento y aseguramiento de la Calidad mediante el cumplimiento de los requisitos de Ley, que por un lado, han adoptado prioritariamente la Norma Técnica de Calidad en la Gestión Pública NTCGP 1000:2009 de acuerdo a la Ley 872 de 2003 y sus respectivos Decretos que la reglamentan y actualizan, y por otra, han acogido los lineamientos de acreditación de alta calidad, estipulados por el Consejo Nacional de Acreditación.

En esta investigación se estudiaron los casos de 16 universidades públicas con el fin de diagnosticar los procesos de aseguramiento y certificación de la calidad, y se pudo establecer que a pesar de haber adelantado procesos de acreditación en alta calidad, abordan de manera separada las normas ISO y los estándares de calidad del CNA.

Es muy importante unificar estos dos sistemas por cuanto los beneficios que se derivan se traducen en mayor bienestar a todos los actores que intervienen en el sistema de educación superior. El Consejo Nacional de Acreditación (s.f.) señala que "algunos de los beneficios que tienen las instituciones, al mantener vigentes las acreditaciones de alta calidad que han obtenido sus programas de pregrado, son el reconocimiento y convalidación de títulos universitarios en otros países, facilidad en los 
procesos de movilidad de sus estudiantes y docentes, entre otros"; de igual manera, cumplir con las exigencias de las normas NTC - ISO se revierte en un mejoramiento continuo, por lo cual es necesario que estas vertientes de calidad se unifiquen para alinear todos los esfuerzos institucionales.

Esta investigación se ha planteado en dos etapas: en la primera, cuyos resultados iniciales se presentan aquí a manera de una tabla denominada "matriz de congruencia", en la que se han unificado los dos sistemas de calidad aplicados a programas de educación superior públicos, y la segunda etapa, que está en proceso de experimentación, consiste en llevar dicha unificación a un modelo de cuadro de mando integral, para simular en un aplicativo los procesos de autoevaluación y gestión estratégica.

\section{FUNDAMENTO TEÓRICO y CONCEPTUAL}

El fundamento conceptual es abordado desde la concepción de la calidad a través de diferentes enfoques, como se muestra en la siguiente tabla:

\section{Tabla 1}

Conceptos de calidad

\begin{tabular}{|c|l|}
\hline Autor & \multicolumn{1}{|c|}{ Definición } \\
\hline Norma ISO 9000 & $\begin{array}{l}\text { La calidad es el "grado en el que un conjunto de características } \\
\text { inherentes cumple con los requisitos", entendiéndose por } \\
\text { requisito "necesidad o expectativa establecida, generalmente } \\
\text { implícita u obligatoria". (Modelo ISO 9001, 2015, p. 1) }\end{array}$ \\
\hline $\begin{array}{c}\text { Ley de Educación } \\
\text { Superior }\end{array}$ & $\begin{array}{l}\text { La calidad "hace referencia a los resultados académicos, } \\
\text { a los medios y procesos empleados, a la infraestructura } \\
\text { institucional, a las dimensiones cualitativas y cuantitativas } \\
\text { del servicio prestado y a las condiciones en que se desarrolla } \\
\text { cada institución." } \\
\text { La calidad actual del sistema de educación superior en nuestro país } \\
\text { "es la resultante de un proceso histórico en que se han conjugado } \\
\text { factores, tanto endógenos como exógenos, que han afectado el } \\
\text { desarrollo de las funciones sustantivas en las instituciones. Basta } \\
\text { recordar los cambios ocurridos a raíz de la promulgación de la Ley } \\
30 \text { del 92 para advertir la dinámica compleja del sistema global } \\
\text { de la educación superior y su heterogeneidad interna." (Consejo } \\
\text { Nacional de Acreditación, s.f., p. 1) }\end{array}$ \\
\hline
\end{tabular}




\begin{tabular}{|c|c|}
\hline $\begin{array}{l}\text { Consejo Nacional } \\
\text { de Acreditación }\end{array}$ & $\begin{array}{l}\text { La calidad "está determinada por la universalidad, la } \\
\text { integridad, la equidad, la idoneidad, la responsabilidad, la } \\
\text { coherencia, la transparencia, la pertinencia, la eficacia y } \\
\text { la eficiencia con que la institución cumple con las grandes } \\
\text { tareas de la educación superior" (Consejo Nacional de } \\
\text { Acreditación, s.f., p. 1) } \\
\text { Es un conjunto de aspectos que permiten reconocer si se } \\
\text { cumplen o no las condiciones para la acreditación institucional. }\end{array}$ \\
\hline $\begin{array}{l}\text { Walter Shewhart, } \\
1931 .\end{array}$ & $\begin{array}{l}\text { La calidad "se trata de una cualidad cuya valoración } \\
\text { dependerá de lo que se perciba, de un producto bien o } \\
\text { servicio." (Shewhart, 1931, p. 3) }\end{array}$ \\
\hline Joseph Juran & $\begin{array}{l}\text { "la calidad es la adecuación de uso de un producto" (Castillo, } \\
2002, \text { p. 298) }\end{array}$ \\
\hline $\begin{array}{l}\text { Besterfield y la } \\
\text { norma a3-1987 } \\
\text { ANSI/ASQC }\end{array}$ & $\begin{array}{l}\text { La calidad "es la totalidad de aspectos y características de } \\
\text { un producto o servicio que permiten satisfacer necesidades } \\
\text { implícitas o explícitamente formuladas." (Summers, 2006, p. } \\
381 \text { ) }\end{array}$ \\
\hline $\begin{array}{l}\text { Mayra R. Moreno } \\
\text { Pino (2003) }\end{array}$ & $\begin{array}{l}\text { La calidad "es el conjunto de características de una entidad } \\
\text { que resultan de un proceso de interacción e integración de } \\
\text { determinados sujetos económicos para permitir satisfacer } \\
\text { y superar las necesidades de los clientes sin afectar el } \\
\text { entorno". Añadir valor, pero valor que sea sostenible. } \\
\text { (Moreno, 2012, p.98) }\end{array}$ \\
\hline
\end{tabular}

Fuente: esta investigación

Para efectos de este estudio se tomó el concepto de calidad como la distancia entre lo que un programa académico de educación superior se propone alcanzar y lo realmente alcanzado, en el marco de los estándares de calidad determinados por el Consejo Nacional de Acreditación y las normas NTC - ISO. 


\section{METODOLOGÍA}

Se consultó a expertos en el tema, se estudiaron varios casos de universidades públicas y sus avances en materia de Sistemas de Gestión de Calidad y se investigó el estado del arte en torno a la unificación de los dos sistemas de calidad, encontrando que los pocos esfuerzos que se han hecho, se centran en las condiciones institucionales de calidad mas no las de los programas académicos. De otra, parte, se participó activamente en procesos de autoevaluación y acreditación de alta calidad en programas de educación superior, así como en las auditorías de ICONTEC en varias universidades.

Con la información sistematizada se procedió a elaborar un paralelo entre las condiciones del CNA y las exigencias de las normas ISO 9000 y NTC GP, con el fin de construir una matriz que representara los elementos concordantes entre ambos, manteniendo la primacía de los lineamientos del CNA, de tal manera que se logren complementar los Factores, Características y Aspectos a evaluar con los requisitos de estas normas.

\section{RESULTADOS}

Se logra consolidar un modelo de articulación de los sistemas de calidad con el fin de dar cumplimiento a los requerimientos de ley, contar con un modelo complementario que oriente los elementos sistémicos y arroje un control para hacer más efectiva la gestión de los procesos educativos. Se plantea el siguiente modelo de articulación de los sistemas de calidad considerando por un lado la norma NTC GP 1000:2009, ISO 9001:2015 desarrollada e implementada actualmente en las universidades públicas y los factores de acreditación para programas de pregrado del CNA.

Se presenta a continuación la matriz descriptiva de la articulación entre los 10 factores y las 40 características del CNA con los 28 requerimientos, con la descripción de la relación de las cuarenta características requeridas por el CNA para programas de pregrado y veintiocho requerimientos de la norma ISO 9001:2015 y la norma NTC GP 100:2009. 


\section{Tabla 2}

\section{Matriz de congruencia}

\begin{tabular}{|c|c|c|c|c|c|}
\hline \multicolumn{2}{|c|}{ CNA PROGRAMAS DE PREGRADO } & \multirow{2}{*}{$\begin{array}{c}\text { Aspectos NTC - ISO } \\
\text { a incluir en Factores } \\
\text { CNA }\end{array}$} & \multirow{2}{*}{ ISO 9001:2015 } & \multirow{2}{*}{$\begin{array}{l}\text { NTC GP } \\
1000: 2009\end{array}$} & \multirow{2}{*}{ RELACIÓN } \\
\hline FACTOR & CARACTERÍSTICA & & & & \\
\hline \multirow[t]{5}{*}{$\begin{array}{l}\text { 1. Misión, } \\
\text { proyecto } \\
\text { institucional y } \\
\text { de programa }\end{array}$} & $\begin{array}{l}\mathrm{N}^{\circ} 1 . \\
\text { Misión, Visión y } \\
\text { Proyecto Institucional }\end{array}$ & \multirow{5}{*}{$\begin{array}{l}\text { Determinación y } \\
\text { documentación } \\
\text { del alcance y la } \\
\text { asignación de } \\
\text { responsabilidades } \\
\text { y autoridades de } \\
\text { los procesos y } \\
\text { procedimientos del } \\
\text { sistema de gestión de } \\
\text { la calidad. } \\
\text { Apropiación del } \\
\text { sistema de Gestión de } \\
\text { calidad por parte de la } \\
\text { comunidad académica } \\
\text { del Programa } \\
\text { Grado de } \\
\text { Correspondencia } \\
\text { entre la visión y la } \\
\text { misión institucional, } \\
\text { los objetivos del } \\
\text { programa académico y } \\
\text { el sistema de gestión } \\
\text { de calidad } \\
\text { Existencia y aplicación } \\
\text { del Sistema de } \\
\text { Gestión de la Calidad, } \\
\text { así como la mejora } \\
\text { continua de su } \\
\text { eficacia, eficiencia y } \\
\text { efectividad. } \\
\text { Grado de } \\
\text { correspondencia } \\
\text { de las políticas de } \\
\text { calidad con el plan } \\
\text { de desarrollo, los } \\
\text { planes sectoriales } \\
\text { y de desarrollo } \\
\text { administrativo, } \\
\text { el Sistema de } \\
\text { Control Interno, los } \\
\text { planes estratégicos } \\
\text { establecidos } \\
\text { Existencia de } \\
\text { disponibilidad de } \\
\text { recursos para la } \\
\text { implementación del } \\
\text { sistema de gestión de } \\
\text { calidad }\end{array}$} & $\begin{array}{l}4.1 \\
\text { Entendiendo la } \\
\text { organización y } \\
\text { su contexto. }\end{array}$ & $\begin{array}{l}5.1 \text { Compromiso } \\
\text { de la dirección }\end{array}$ & \multirow{5}{*}{$\begin{array}{l}\text { El CNA reconoce } \\
\text { la importancia de } \\
\text { la socialización y } \\
\text { apropiación del proyecto } \\
\text { institucional y del } \\
\text { programa por parte de } \\
\text { la comunidad y sirve de } \\
\text { referente fundamental } \\
\text { para el desarrollo de sus } \\
\text { funciones misionales y en } \\
\text { complemento la Norma } \\
\text { ISO y NTC establecen } \\
\text { las cuestiones tanto } \\
\text { externas como internas } \\
\text { que son pertinentes } \\
\text { para cumplimento del } \\
\text { propósito, dirección } \\
\text { estratégica y resultados } \\
\text { previstos para el Sistema } \\
\text { de Gestión de la Calidad. } \\
\text { De igual forma es } \\
\text { primordial asegurar } \\
\text { de que las personas } \\
\text { que llevan a cabo un } \\
\text { trabajo bajo el control } \\
\text { de la empresa tomen } \\
\text { conciencia sobre: todos } \\
\text { los procesos de sistemas } \\
\text { de gestión de calidad y la } \\
\text { consecución de la misión } \\
\text { y visión institucional } \\
\text { y del programa. (7.3 } \\
\text { Concienciación) }\end{array}$} \\
\hline & & & $\begin{array}{l}4.4 \\
\text { Sistema de } \\
\text { Gestión de } \\
\text { Calidad. }\end{array}$ & & \\
\hline & $\begin{array}{l}\mathrm{N}^{\circ} 2 . \\
\text { Proyecto Educativo }\end{array}$ & & $\begin{array}{l}7.3 \\
\text { Concienciación. }\end{array}$ & & \\
\hline & & & $\begin{array}{l}4.3 \\
\text { Establecimiento } \\
\text { del alcance } \\
\text { del Sistema } \\
\text { de Gestión de } \\
\text { Calidad. }\end{array}$ & & \\
\hline & $\begin{array}{l}\mathrm{N}^{\circ} 3 . \\
\text { Relevancia } \\
\text { académica y } \\
\text { pertinencia social del } \\
\text { programa }\end{array}$ & & $\begin{array}{l}4.2 \\
\text { Entendiendo } \\
\text { las necesidades } \\
\text { y expectativas } \\
\text { de las partes } \\
\text { interesadas. }\end{array}$ & $\begin{array}{l}5.3 \text { Política de la } \\
\text { calidad }\end{array}$ & \\
\hline
\end{tabular}




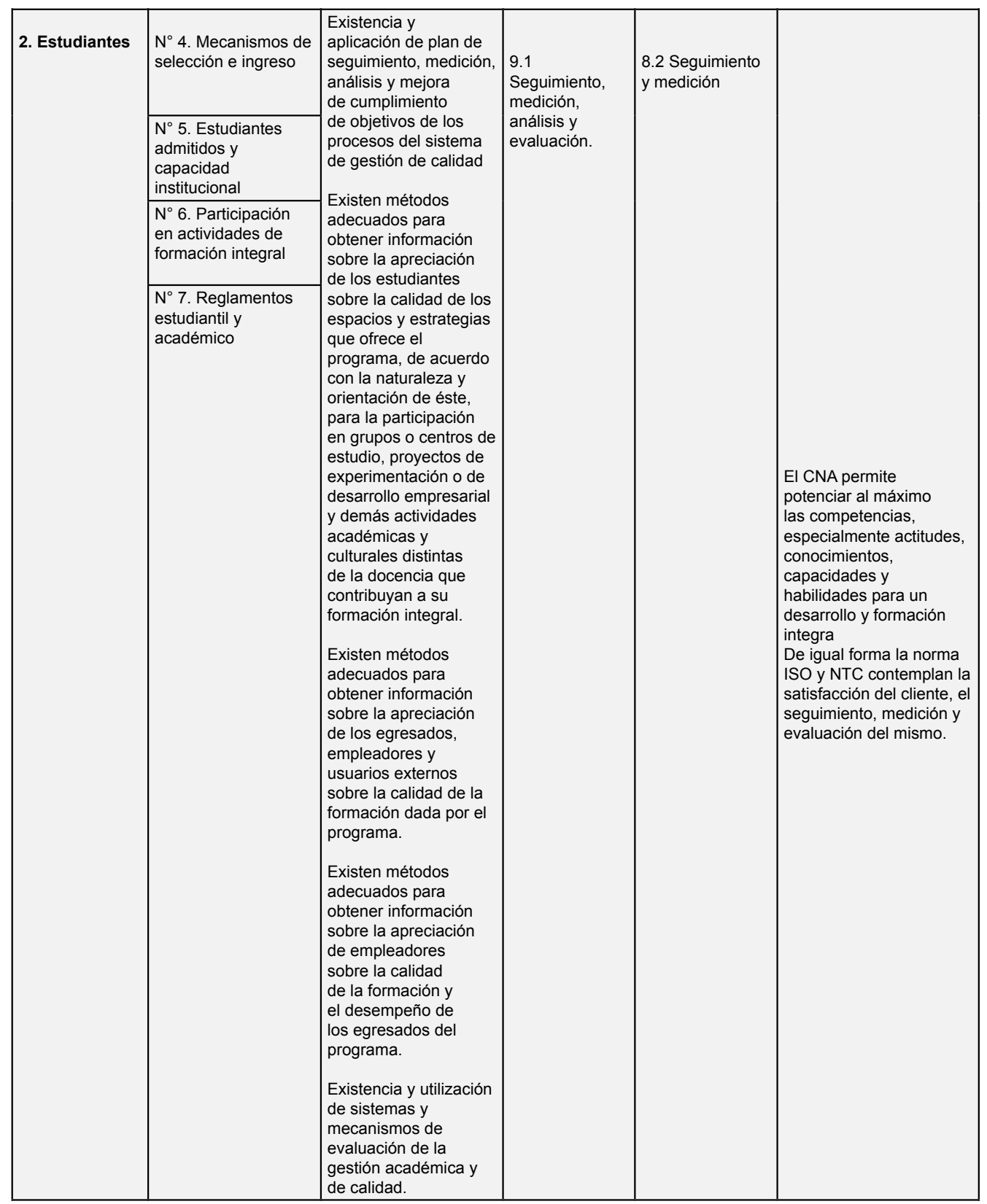


Articulación de los sistemas de calidad, Consejo Nacional de Acreditación (cna) y normas ntc - iso 9001 para programas académicos de educación superior en instituciones públicas

Gonzalez Muñoz _ Ingrid Brigitt, Ramirez Gomez_Carlos Arturo

\begin{tabular}{|c|c|c|c|c|c|}
\hline \multirow[t]{8}{*}{ 3. Profesores } & $\begin{array}{l}N^{\circ} \text { 8. Selección, } \\
\text { vinculación y } \\
\text { permanencia de } \\
\text { profesores }\end{array}$ & \multirow{8}{*}{$\begin{array}{l}\text { Apropiación y } \\
\text { empoderamiento de } \\
\text { comunidad académica } \\
\text { sobre la formación } \\
\text { profesional integral } \\
\\
\text { Los servidores } \\
\text { públicos y /o } \\
\text { particulares que } \\
\text { ejercen funciones } \\
\text { públicas son } \\
\text { competentes de } \\
\text { acuerdo con la } \\
\text { educación, formación } \\
\text { habilidades y } \\
\text { experiencia. } \\
\\
\text { Existencia de registros } \\
\text { de la educación, } \\
\text { formación habilidades } \\
\text { y experiencias de los } \\
\text { servidores públicos y } \\
\text { /o particulares. }\end{array}$} & 7.1 Recursos. & \multirow[t]{8}{*}{\begin{tabular}{|l}
6.2 Talento \\
humano
\end{tabular}} & \multirow{3}{*}{\begin{tabular}{|l|} 
El CNA se enfoca en la \\
calidad de los profesores, \\
teniendo en cuenta la \\
aplicación de políticas y \\
programas de desarrollo \\
profesoral adecuados \\
a la metodología, \\
las necesidades y \\
objetivos, sin dejar \\
de lado los estímulos, \\
remuneraciones y \\
seguimiento y evaluación \\
de los mismos. \\
\end{tabular}} \\
\hline & $\begin{array}{l}N^{\circ} 9 . \text { Estatuto } \\
\text { profesoral }\end{array}$ & & & & \\
\hline & $\begin{array}{l}N^{\circ} 10 . \text { Número, } \\
\text { dedicación, nivel } \\
\text { de formación y } \\
\text { experiencia de los } \\
\text { profesores } \\
\end{array}$ & & $\begin{array}{l}7.2 \\
\text { Competencia }\end{array}$ & & \\
\hline & $\begin{array}{l}N^{\circ} \text { 11. Desarrollo } \\
\text { profesoral }\end{array}$ & & & & $\begin{array}{l}\text { La ISO en El apartado } \\
7.1 .2 \text { requiere que se } \\
\text { cuente con el personal } \\
\text { necesario para realizar }\end{array}$ \\
\hline & $\begin{array}{l}N^{\circ} 12 . \text { Estímulos } \\
\text { a la docencia, } \\
\text { investigación, } \\
\text { creación artística y } \\
\text { cultural, extensión } \\
\text { o proyección social } \\
\text { y a la cooperación } \\
\text { internacional } \\
\end{array}$ & & & & $\begin{array}{l}\text { un funcionamiento } \\
\text { eficiente del Sistema de } \\
\text { Gestión de la Calidad y } \\
\text { de todos los procesos } \\
\text { con el fin de cumplir de } \\
\text { forma constante con } \\
\text { todos los requisitos } \\
\text { legales y los reglamentos }\end{array}$ \\
\hline & $\begin{array}{l}N^{\circ} 13 . \text { Producción, } \\
\text { pertinencia, } \\
\text { utilización e impacto } \\
\text { de material docente } \\
\end{array}$ & & & & $\begin{array}{l}\text { con la respectiva } \\
\text { medición y control de los } \\
\text { mismos. } \\
\text { La competencia en la }\end{array}$ \\
\hline & $\begin{array}{l}N^{\circ} \text { 14. Remuneración } \\
\text { por méritos }\end{array}$ & & & & $\begin{array}{l}\text { capacidad del talento } \\
\text { humano con la que se } \\
\text { aplica los conocimientos }\end{array}$ \\
\hline & $\begin{array}{l}\mathrm{N}^{\circ} 15 . \text { Evaluación de } \\
\text { profesores }\end{array}$ & & & & $\begin{array}{l}\text { y las habilidades con } \\
\text { el fin de conseguir los } \\
\text { resultados previstos. }\end{array}$ \\
\hline
\end{tabular}




\begin{tabular}{|c|c|c|c|c|c|}
\hline \multirow[t]{12}{*}{$\begin{array}{l}\text { 4. Procesos } \\
\text { académicos }\end{array}$} & \multirow[t]{2}{*}{$\begin{array}{l}N^{\circ} 16 . \text { Integralidad } \\
\text { del currículo }\end{array}$} & $\begin{array}{l}\text { Existencia de } \\
\text { mecanismos de } \\
\text { evaluación de las } \\
\text { actualizaciones a la } \\
\text { integridad curricular }\end{array}$ & \multirow[t]{3}{*}{$\begin{array}{l}8.1 \\
\text { Planificación } \\
\text { y control } \\
\text { operacional. }\end{array}$} & \multirow[t]{3}{*}{$\begin{array}{l}\text { 7.1 Planificación } \\
\text { de la realización } \\
\text { del producto o } \\
\text { prestación del } \\
\text { servicio }\end{array}$} & $\begin{array}{l}\text { El CNA se enfoca en: } \\
\text { La formación integral, } \\
\text { flexible, actualizada e } \\
\text { interdisciplinar, acorde } \\
\text { con las tendencias } \\
\text { contemporáneas del área } \\
\text { disciplinar o profesional }\end{array}$ \\
\hline & & \multirow{4}{*}{\multicolumn{2}{|c|}{ 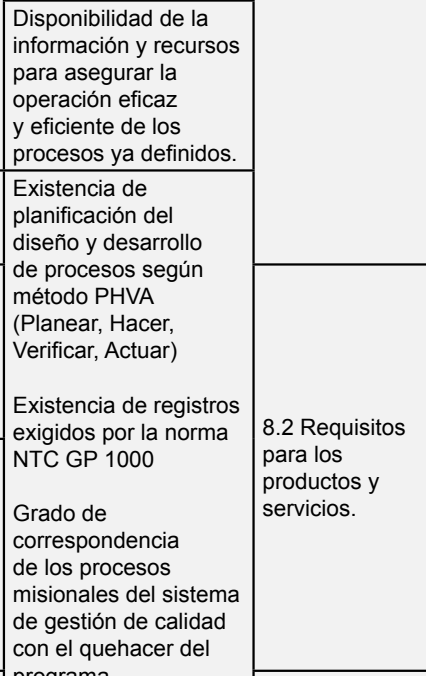 }} & & \multirow{7}{*}{$\begin{array}{l}\text { Estimular la interacción } \\
\text { de estudiantes y } \\
\text { profesores de distintos } \\
\text { programas y de otras } \\
\text { áreas de conocimiento } \\
\text { Fomentar la } \\
\text { investigación, el espíritu } \\
\text { crítico y la creación de } \\
\text { aportes al conocimiento } \\
\text { científico, a la innovación } \\
\text { y al desarrollo cultural. } \\
\text { Influenciar positivamente } \\
\text { sobre el entorno a } \\
\text { nivel regional, nacional } \\
\text { e internacional, en } \\
\text { el desarrollo de } \\
\text { políticas definidas y en } \\
\text { correspondencia con su } \\
\text { naturaleza y su situación } \\
\text { específica. } \\
\text { Enfrentar } \\
\text { académicamente } \\
\text { problemas y } \\
\text { oportunidades del } \\
\text { entorno, para evaluar su } \\
\text { pertinencia, promover el } \\
\text { vínculo con los distintos } \\
\text { sectores de la sociedad, } \\
\text { el sector productivo, el } \\
\text { Sistema Nacional de } \\
\text { Ciencia y Tecnología } \\
\text { y el Sistema Nacional } \\
\text { de Formación para el } \\
\text { Trabajo. } \\
\text { Todo esto de la mano } \\
\text { de los procesos } \\
\text { de Evaluación y } \\
\text { autorregulación y del } \\
\text { contar con los recursos } \\
\text { y el ambiente apropiado } \\
\text { para el desarrollo de } \\
\text { todos los procesos. } \\
\end{array}$} \\
\hline & $\begin{array}{l}\mathrm{N}^{\circ} 17 \text {. Flexibilidad del } \\
\text { currículo }\end{array}$ & & & & \\
\hline & $\begin{array}{l}\mathrm{N}^{\circ} 18 . \\
\text { Interdisciplinariedad }\end{array}$ & & & & \\
\hline & $\begin{array}{l}N^{\circ} 19 . \text { Estrategias } \\
\text { de enseñanza y } \\
\text { aprendizaje }\end{array}$ & & & $\begin{array}{l}\text { de bienes y } \\
\text { servicios }\end{array}$ & \\
\hline & $\begin{array}{l}\mathrm{N}^{\circ} \text { 20. Sistema } \\
\text { de evaluación de } \\
\text { estudiantes }\end{array}$ & \multirow{7}{*}{$\begin{array}{l}\text { Existencia y } \\
\text { aplicación de registros } \\
\text { funcionales y de } \\
\text { desempeño de los } \\
\text { procesos realizados. } \\
\text { Existencia de } \\
\text { mecanismos de control } \\
\text { de los elementos } \\
\text { resultantes del } \\
\text { proceso, los productos } \\
\text { y los servicios no } \\
\text { conformes } \\
\text { Existencia de } \\
\text { procedimiento } \\
\text { documentado que } \\
\text { incluya la aprobación } \\
\text { de los documentos } \\
\text { para verificar la } \\
\text { suficiencia antes de la } \\
\text { edición. } \\
\text { Existencia de } \\
\text { procedimiento } \\
\text { documentado que } \\
\text { incluya la revisión, } \\
\text { actualización y } \\
\text { reaprobación de los } \\
\text { documentos }\end{array}$} & \multirow{2}{*}{$\begin{array}{l}8.3 \text { Diseño y } \\
\text { desarrollo de } \\
\text { los productos y } \\
\text { servicios. }\end{array}$} & \multirow{6}{*}{$\begin{array}{l}\text { 7.3 Diseño y } \\
\text { desarrollo }\end{array}$} & \\
\hline & $\begin{array}{l}\mathrm{N}^{\circ} 21 . \text { Trabajos de } \\
\text { los estudiantes }\end{array}$ & & & & \\
\hline & $\begin{array}{l}\mathrm{N}^{\circ} 22 \text {. Evaluación y } \\
\text { autorregulación del } \\
\text { programa }\end{array}$ & & \multirow{4}{*}{$\begin{array}{l}8.5 \text { Producción } \\
\text { y provisión del } \\
\text { servicio. }\end{array}$} & & \\
\hline & $\begin{array}{l}\text { №23. Extensión o } \\
\text { proyección social }\end{array}$ & & & & \\
\hline & $\begin{array}{l}N^{\circ} 24 . \text { Recursos } \\
\text { bibliográficos }\end{array}$ & & & & \\
\hline & $\begin{array}{l}\mathrm{N}^{\circ} 25 . \text { Recursos } \\
\text { informáticos y de } \\
\text { comunicación }\end{array}$ & & & & \\
\hline & $\begin{array}{l}\mathrm{N}^{\circ} 26 . \text { Recursos de } \\
\text { apoyo docente }\end{array}$ & & & & \\
\hline
\end{tabular}


Articulación de los sistemas de calidad, Consejo Nacional de Acreditación (cna) y normas ntc - iso 9001 para programas académicos de educación superior en instituciones públicas

\begin{tabular}{|c|c|c|c|c|c|}
\hline & & \begin{tabular}{|l|} 
Existencia de \\
procedimiento \\
documentado que \\
incluya la identificación \\
de los cambios y la \\
revisión vigente. \\
Existencia de \\
procedimiento \\
documentado \\
que incluya la \\
disponibilidad en los \\
puntos de uso de las \\
versiones pertinentes \\
de la documentación \\
aplicable. \\
Existencia de \\
procedimiento \\
documentado \\
que incluya los \\
mecanismos para \\
asegurar la legibilidad \\
y la fácil identificación \\
de los documentos \\
Identificación e \\
implementación \\
de disposiciones \\
legales que les \\
sean aplicables \\
a la institución \\
sobre el control de \\
documentos.
\end{tabular} & $\begin{array}{l}8.7 \text { Control de } \\
\text { las salidas no } \\
\text { conformes. }\end{array}$ & \multirow[t]{5}{*}{$\begin{array}{l}8.3 \text { Control } \\
\text { del producto } \\
\text { y/o servicio no } \\
\text { conforme }\end{array}$} & \multirow[t]{5}{*}{$\begin{array}{l}\text { La norma ISO y NTC } \\
\text { inicialmente plantean: } \\
\text { La planificación para } \\
\text { implementar y controlar } \\
\text { todos los procesos. } \\
\text { Revisión de } \\
\text { requerimientos tanto } \\
\text { del cliente como } \\
\text { condiciones internas } \\
\text { y externas necesarias } \\
\text { para el desarrollo de los } \\
\text { procesos. } \\
\text { El establecer, implantar y } \\
\text { mantener el proceso de } \\
\text { diseño y desarrollo que } \\
\text { sea el adecuado para } \\
\text { asegurarse de que se } \\
\text { cumpla con la ejecución } \\
\text { y desarrollo adecuado de } \\
\text { los procesos. } \\
\text { Asegurar de que los } \\
\text { productos, procesos } \\
\text { y servicios que se } \\
\text { suministran de forma } \\
\text { externa se encuentran } \\
\text { conformes a los } \\
\text { requisitos. } \\
\text { Implantación de } \\
\text { disposiciones } \\
\text { planificadas, en las } \\
\text { etapas adecuadas, } \\
\text { verificando que se } \\
\text { cumplan todos los } \\
\text { requisitos. }\end{array}$} \\
\hline \multirow[t]{2}{*}{$\begin{array}{l}\text { 5. Visibilidad } \\
\text { nacional e } \\
\text { internacional }\end{array}$} & $\begin{array}{l}\mathrm{N}^{\circ} 27 \text {. Inserción } \\
\text { del programa } \\
\text { en contextos } \\
\text { académicos } \\
\text { nacionales e } \\
\text { internacionales }\end{array}$ & \multirow{4}{*}{$\begin{array}{l}\text { Existencia y aplicación } \\
\text { de mecanismos } \\
\text { de control de los } \\
\text { productos y servicios } \\
\text { proporcionados } \\
\text { externamente } \\
\text { Existencia y aplicación } \\
\text { de políticas de } \\
\text { comunicación efectiva }\end{array}$} & \multirow{4}{*}{$\begin{array}{l}8.4 \text { Control de } \\
\text { los procesos, } \\
\text { productos } \\
\text { y servicios } \\
\text { suministrados } \\
\text { externamente. }\end{array}$} & & \\
\hline & $\begin{array}{l}\mathrm{N}^{\circ} 28 \text {. Relaciones } \\
\text { externas de } \\
\text { profesores y } \\
\text { estudiantes. }\end{array}$ & & & & \\
\hline \multirow[t]{2}{*}{$\begin{array}{c}6 . \\
\text { Investigación, } \\
\text { innovación } \\
\text { y creación } \\
\text { artística y } \\
\text { cultural }\end{array}$} & $\begin{array}{l}\mathrm{N}^{\circ} 29 \text {. Formación } \\
\text { para la investigación, } \\
\text { la innovación y la } \\
\text { creación artística y } \\
\text { cultural }\end{array}$ & & & & \\
\hline & $\begin{array}{l}\mathrm{N}^{\circ} 30 \text {. Compromiso } \\
\text { con la investigación y } \\
\text { la creación artística y } \\
\text { cultural }\end{array}$ & & & & \\
\hline \multirow[t]{2}{*}{$\begin{array}{l}\text { 7. Bienestar } \\
\text { institucional }\end{array}$} & $\begin{array}{l}\mathrm{N}^{\circ} 31 . \text { Políticas, } \\
\text { programas y } \\
\text { servicios de bienestar } \\
\text { universitario }\end{array}$ & & \multirow[t]{2}{*}{ 7.1 Recursos. } & \multirow[t]{2}{*}{$\begin{array}{l}\text { 6.4 Ambiente de } \\
\text { trabajo }\end{array}$} & \multirow{2}{*}{$\begin{array}{l}\text { En el CNA los servicios } \\
\text { de bienestar universitario } \\
\text { además de ser un } \\
\text { apoyo a la formación } \\
\text { integral, estos deben ser } \\
\text { suficientes, adecuados } \\
\text { y accesibles a todo } \\
\text { el personal y deben } \\
\text { responder a una política } \\
\text { integral de bienestar } \\
\text { universitario definida por } \\
\text { la institución. }\end{array}$} \\
\hline & $\begin{array}{l}N^{\circ} 32 . \text { Permanencia } \\
\text { y retención estudiantil }\end{array}$ & & & & \\
\hline
\end{tabular}




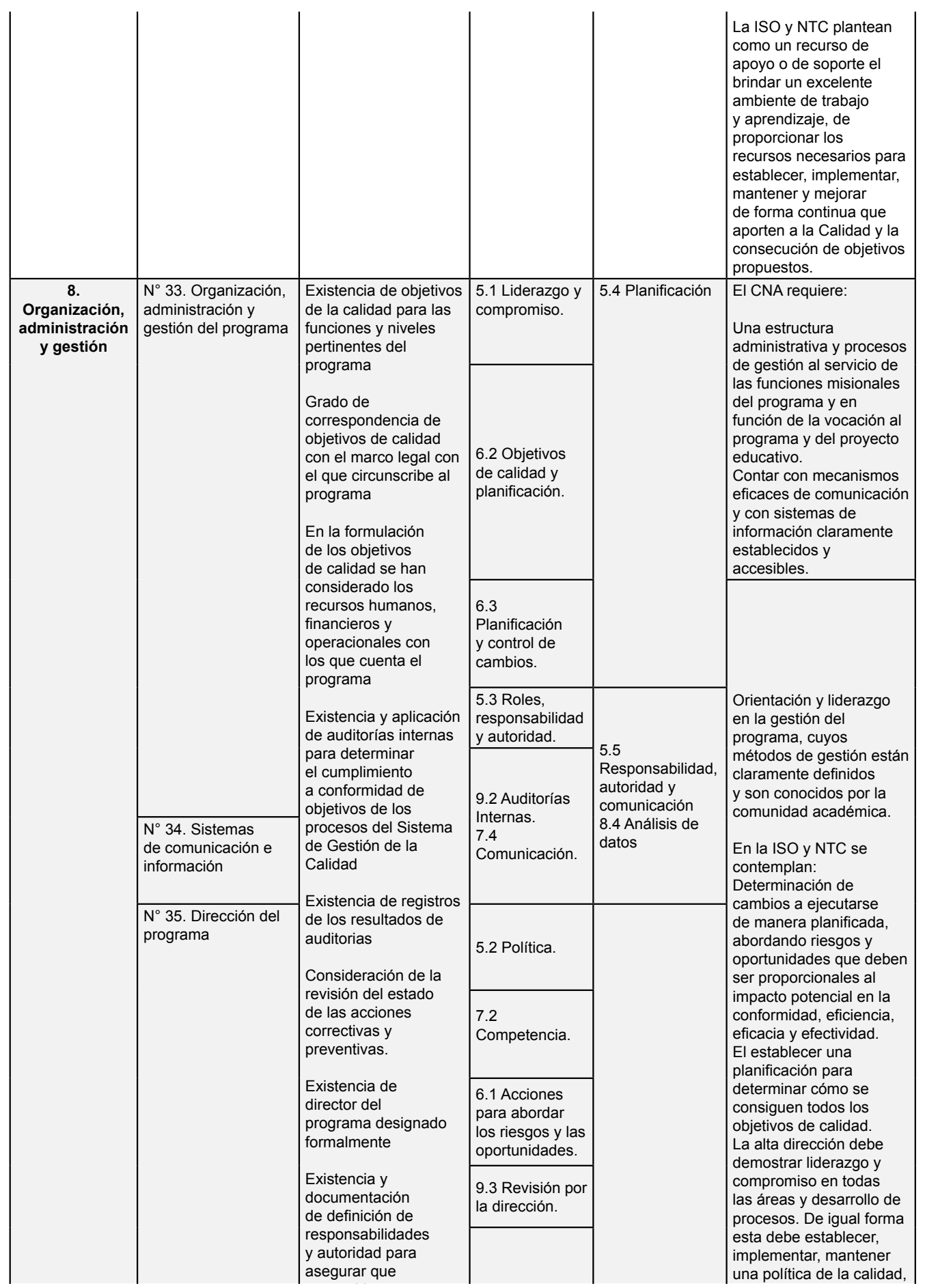




\begin{tabular}{|c|c|c|c|c|c|}
\hline & & $\begin{array}{l}\text { se establezcan. } \\
\text { Implementen y se } \\
\text { mantengan los } \\
\text { procesos necesarios } \\
\text { para el sistema de } \\
\text { gestión de calidad } \\
\text { Existencia y } \\
\text { documentación } \\
\text { de definición de } \\
\text { responsabilidades } \\
\text { y autoridad para } \\
\text { informar a la dirección } \\
\text { sobre el desempeño } \\
\text { de los procesos de } \\
\text { calidad y cualquier } \\
\text { necesidad de mejora } \\
\text { para el sistema de } \\
\text { gestión de calidad } \\
\text { Existencia de revisión } \\
\text { de la evaluación de } \\
\text { las oportunidades de } \\
\text { mejora } \\
\text { Existencia de registros } \\
\text { de las revisiones de la } \\
\text { dirección } \\
\text { Existencia de revisión } \\
\text { concluyente respecto } \\
\text { a la conveniencia, } \\
\text { adecuación, eficiencia, } \\
\text { eficacia y efectividad } \\
\text { del sistema de gestión } \\
\text { de calidad. }\end{array}$ & $\begin{array}{l}7.5 \text { Información } \\
\text { documentada }\end{array}$ & $\begin{array}{l}\text { 5.6 Revisión por } \\
\text { la dirección }\end{array}$ & $\begin{array}{l}\text { y asegurarse de que } \\
\text { las responsabilidades } \\
\text { y autoridades para } \\
\text { los roles pertinentes } \\
\text { quedan asignadas, } \\
\text { se comuniquen y se } \\
\text { entiendan en toda la } \\
\text { organización. } \\
\text { La competencia en la } \\
\text { capacidad del talento } \\
\text { humano con la que se } \\
\text { aplica los conocimientos } \\
\text { y las habilidades con } \\
\text { el fin de conseguir los } \\
\text { resultados previstos. } \\
\text { Realización de auditorias } \\
\text { internas dentro de } \\
\text { unos intervalos de } \\
\text { tiempo planificados, } \\
\text { de ellas se obtendrá } \\
\text { información muy valiosa } \\
\text { para direccionamiento } \\
\text { estratégico. } \\
\text { La información } \\
\text { documentada se } \\
\text { conserva como evidencia } \\
\text { de la conformidad, se } \\
\text { tiene que proteger frente } \\
\text { a posibles modificaciones } \\
\text { no autorizadas. }\end{array}$ \\
\hline $\begin{array}{l}\text { 9. Impacto de } \\
\text { los egresados } \\
\text { en el medio }\end{array}$ & $\begin{array}{l}\mathrm{N}^{\circ} 36 . \text { Seguimiento } \\
\text { de los egresados }\end{array}$ & \begin{tabular}{|l} 
Existencia y \\
aplicación de \\
métodos adecuados \\
de encuestas de \\
satisfacción al cliente. \\
\\
Existencia de métodos \\
de seguimiento y \\
control de encuestas \\
de satisfacción
\end{tabular} & \begin{tabular}{|l} 
\\
\\
9.2 \\
$\begin{array}{l}\text { Seguimiento, } \\
\text { medición, } \\
\text { análisis y } \\
\text { evaluación. }\end{array}$
\end{tabular} & $\begin{array}{l}\begin{array}{l}\text { 5.2 Enfoque al } \\
\text { cliente }\end{array} \\
8.5 \text { Mejora }\end{array}$ & $\begin{array}{l}\text { En el CNA, el } \\
\text { desempeño laboral de } \\
\text { los egresados y del } \\
\text { impacto que éstos tienen } \\
\text { en el proyecto académico } \\
\text { y en los procesos de } \\
\text { desarrollo social, cultural } \\
\text { y económico en sus } \\
\text { respectivos entornos. } \\
\text { Se debe realizar } \\
\text { seguimiento a la } \\
\text { ubicación y a las } \\
\text { actividades que } \\
\text { desarrollan los egresados } \\
\text { en asuntos concernientes } \\
\text { al logro de los fines } \\
\text { de la institución y del } \\
\text { programa. } \\
\text { La ISO y NTC plantean } \\
\text { el asegurar de que las } \\
\text { salidas que no estén } \\
\text { conformes con los } \\
\text { requisitos, se identifiquen } \\
\text { y se controlen con } \\
\text { una posterior toma de } \\
\text { decisiones basadas en } \\
\text { la naturaleza de la no } \\
\text { conformidad que impide } \\
\text { el cumplimiento de metas } \\
\text { y objetivos. }\end{array}$ \\
\hline
\end{tabular}




\begin{tabular}{|c|c|c|c|c|c|}
\hline & $\begin{array}{l}\mathrm{N}^{\circ} 37 . \text { Impacto de } \\
\text { los egresados en } \\
\text { el medio social y } \\
\text { académico }\end{array}$ & & & & $\begin{array}{l}\text { Contemplan también la } \\
\text { satisfacción del cliente, el } \\
\text { seguimiento, medición y } \\
\text { evaluación del mismo. }\end{array}$ \\
\hline \multirow[t]{3}{*}{$\begin{array}{l}\text { 10. Recursos } \\
\text { físicos y } \\
\text { financieros }\end{array}$} & $\begin{array}{l}N^{\circ} \text { 38. Recursos } \\
\text { físicos }\end{array}$ & \multirow{3}{*}{$\begin{array}{l}\text { Existen registros } \\
\text { de vida útil de los } \\
\text { bienes, equipos e } \\
\text { infraestructura. } \\
\text { Existencia y aplicación } \\
\text { de métodos de } \\
\text { manejo, seguimiento y } \\
\text { de control de entradas } \\
\text { y salidas de recursos. } \\
\text { Existencia de registros } \\
\text { de todos los procesos } \\
\text { y procedimientos } \\
\text { realizados en } \\
\text { presupuestos y } \\
\text { adquisición de } \\
\text { recursos físicos. }\end{array}$} & \multirow[t]{3}{*}{ 7.1 Recursos. } & $\begin{array}{l}6.1 \text { Provisión de } \\
\text { recursos }\end{array}$ & \multirow{3}{*}{$\begin{array}{l}\text { En el CNA, se plantea } \\
\text { que se debe garantizar } \\
\text { y presupuestar los } \\
\text { recursos necesarios } \\
\text { para dar cumplimiento } \\
\text { óptimo al proyecto } \\
\text { educativo y por mostrar } \\
\text { una ejecución y manejo } \\
\text { efectivos y transparentes } \\
\text { de sus recursos físicos y } \\
\text { financieros. } \\
\text { En la norma ISO y NTC, } \\
\text { se tienen en cuenta todos } \\
\text { los recursos internos y } \\
\text { externos, por lo que se } \\
\text { incorpora el concepto de } \\
\text { servicios subcontratados. } \\
\text { El proporcionar los } \\
\text { recursos necesarios para } \\
\text { establecer, implementar, } \\
\text { mantener y mejorar de } \\
\text { forma continua, al igual } \\
\text { se debe proporcionar } \\
\text { y mantener la } \\
\text { infraestructura necesaria } \\
\text { para que los procesos } \\
\text { operen con eficiencia. }\end{array}$} \\
\hline & $\begin{array}{l}\mathrm{N}^{\circ} 39 . \text { Presupuesto } \\
\text { del programa }\end{array}$ & & & 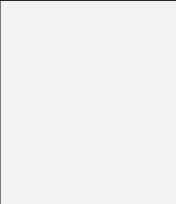 & \\
\hline & $\begin{array}{l}N^{\circ} 40 \text {. Administración } \\
\text { de recursos }\end{array}$ & & & $\begin{array}{l}6.3 \\
\text { Infraestructura }\end{array}$ & \\
\hline
\end{tabular}

\section{CONCLUSIONES Y DISCUSIÓN}

El modelo propuesto de articulación de la calidad académica y administrativa complementa en doble vía los elementos del sistema de acreditación para programas de pregrado del CNA con el enfoque sistémico del sistema de gestión de la calidad de la norma ISO 9001:2015y NTC GP 1000:2009. Tiene como objetivo servir como mecanismo para la acreditación en alta calidad teniendo en cuenta el mejoramiento continuo originando un cambio de una cultura de calidad con escalonamiento hacia la excelencia.

En el modelo de articulación se puede observar cómo los dos sistemas de calidad se complementan y que es muy viable la ejecución de la unificación de estos en pro a la consecución de la calidad.

Esta nueva formulación que articula los sistemas de calidad existentes, permite solventar los conflictos en las relaciones que se dan entre estos y propende por la coherencia de sus resultados, lo cual coadyuva a asegurar la excelencia académica. 
Después de esta matriz de concordancia se debe construir un modelo de cuadro de mando integral que pueda llevarse a un aplicativo, para desarrollar experimentalmente un modelo estratégico de autoevaluación y gestión conducente a la acreditación de alta calidad de los programas. En este sentido, la investigación se halla en la etapa de experimentación con el aplicativo de Sixtina, cuyos resultados se presentarán en otra disertación.

\section{REFERENCIAS}

(1) Acreditación, C. N. A. (Enero de 2013). Lineamientos Para La Acreditación De Programas De Pregrado. Obtenido de http://www.cna.gov.co/1741/ articles-186359_pregrado_2013.pdf

(2) Consejo Nacional de Acreditación. (s.f.). Obtenido de http://www.cna.gov. co/1741/article-190811.html

(3) Durán, M. U. (1992). Gestión de la Calidad. Madrid: Diaz de Santos, S.A.

(4) ISO 9001:2015. (s.f.). Obtenido de http://www.nueva-iso-9001-2015.com/

(5) Modelo ISO 9001. (2012). Obtenido de http://queaprendemoshoy. com/\%C2\%BFque-es-la-calidad-vi-el-modelo-iso-9001-de-gestion-de-lacalidad/

(6) NTC GP 1000:2009. (s.f.).

(7) Quiles, I. (1945). Isodoro de Sevilla. Argentina.

(8) Shewhart, W. (s.f.). Introducción a la calidad. En C. F. Mazziotta, Gestión de la Calidad.

(9) Summers, D. C. (2006). Administración de la Calidad. Mexico: Pearson Educación

(10) Levy- Leboyer, C. (1997), "Gestión de las Competencias", Barcelona, Gestión 2000. 
(11) Pedraza, X. (2010) Aporte del enfoque sistémico del modelo de gestión de la calidad NTC ISO 9001 al modelo de acreditación institucional en instituciones privadas de educación superior. Universidad Santo Tomás e ICONTEC. Colombia. 15 págs.

(12) Stufflebeam, D. L. y Shinkfield, A. J. (1987). Evaluación sistemática. Guía teórica y práctica. Barcelona: Paidos/MEC. 